\title{
DEVELOPING TRANSLATION COMPETENCE WITHIN THE LIFELONG LEARNING PROGRAMME FOR LAWYER-LINGUISTS IN THE REPUBLIC OF CROATIA
}

\begin{abstract}
Translation competence includes a complex variety of cognitive, linguistic and cultural skills. Translation in the field of law represents an even more demanding process, as it can be defined as "an act of communication in the mechanism of law" which leads "to legal effects and may induce peace or a prompt war" (Šarčević, 1997). In this paper, different aspects of the translator's competence in legal translation are discussed. In the introductory part, an overview of theoretical approaches to the translation process is offered. The main part of the paper is dedicated to problems and challenges that legal translators are faced with. Special attention is paid to teaching the documentary approach to translation of EU legislation within the Lifelong Learning Programme for Lawyer-Linguists in the Republic of Croatia. The problems occurring in legal translation and competences of legal translators are discussed from the teacher's perspective, based on the experience in teaching the course Introduction to the Theory of Legal Translation and Terminology within the Lifelong Learning Programme for Lawyer-Linguists at the Faculty of Law, University of Osijek, Croatia.

Keywords: translation competence, legal translation, documentary approach, lifelong learning
\end{abstract}

\section{Introduction}

\section{On the contents and the goal of the paper}

In this paper the author discusses the competences of translators necessary in the field of legal translation. In the introductory part an overview of theoretical approaches to legal translation is offered, with special reference to the functionalist approach, whose representatives observe translation in the field of law from a sociocultural perspective. The second part of the paper is dedicated to the teaching of legal translation in tertiary education in the Republic of Croatia, shown on the example of the Life- 


\section{Ljubica Kordić}

long Learning Programme for legal translators ("lawyer-linguists"), developed several years ago at the Faculty of Law, University of Osijek. Special attention is paid to the contents and methodology of teaching legal translation and developing the necessary competences in future legal translators in the subject Introduction to the Theory of Legal Translation and Terminology, which is delivered within this education programme. In the concluding part, the advantages and disadvantages of the Lifelong Learning Programme for Lawyer-Linguists are discussed, with a focus on the competences being developed in the participants of the Programme. The main goal of the theoretical part of the paper is to present the complexity and specific features of legal translation and to determine competences that the experts dealing with translation in the field of law should possess. A specific approach to the development of those competences is shown by analysing the syllabus of the Lifelong Learning Programme for Lawyer-Linguists, especially the subject Introduction to the Theory of Legal Translation and Terminology.

\section{Theoretical approaches to translation with specific reference to legal translation}

According to Susan Šarčević, translation in the field of law represents "...an act of communication in the mechanism of law" which leads "to legal effects and may induce peace or a prompt war" (Šarčević, 1997). Until the 1970's, the most common approach to translation was based on the concept of equivalence of terms in the source language and the target language. In the 1970's it was put aside as secondary, especially in the context of legal translation, because differences in legal systems and cultures were for the first time seen as a relevant factor in this type of specialized translation. Gideon Toury was one of the first to observe translation in the sociocultural context of the target language and target culture, and to stress the importance of extra-linguistic factors, which strongly influence the translation process in the field of law (Baker/Saldanha, 2009).

This idea was further developed by the German translation school. Its well-known representatives Katarina Reiss and Hans Vermeer observe legal translation as a specific type of cultural transfer ("Sondersorte des kulturellen Transfers"), arguing that in the process of translation in the field of law legal contents are transferred from one legal system and one culture into another (Reiss/Vermeer, 1984: 13).

The theoretical approach developed by Reiss and Vermeer became well known as the functionalist approach. The main principle of this approach is the interdependence of the translation method and the function of the 
text, set by Katharina Reiss. According to the criterion of the function of the texts to be translated, she established the distinction between informative, expressive and operative text types. This approach was further elaborated by Hans Vermeer, who developed the so called "Skopos-theory": the purpose of translation, the target language and the final user of the translation are seen as main factors of the translation process. He argues that one text may be approached in quite different ways depending on the requirements of the recipient. A normative text, like the ordinance or the statute of a firm or company, is not to be translated in the same way and with the same precision if the translation should function in the target language as a firm's document, or if it is translated for informative (private) purposes. Accordingly, Christiane Nord distinguishes between two main types of translation depending on their function: documentary, serving as a document in communication between the source and the target culture, and instrumental, serving for communicative function in the TL (Nord, 1997).

\section{Translator's competences with specific reference to legal translation}

Translation competence is defined as a construct consisting of knowledge, skills and attitudes necessary for translation task realization (Kelly, 2005: 162). According to the same author, skills and attitudes are built of specific sub-competences: communicative and textual sub-competence, cultural and intercultural sub-competence, subject area sub-competence, as well as professional and instrumental, psychophysiological, strategic, and interpersonal sub-competences (Kelly, 2005).

Susan Šarčević takes a step forward and creates a list of specific competences necessary in legal translation. The list includes:

- knowledge of legal terminology,

- in-depth understanding of logical principles,

- logical reasoning,

- the ability of problem-solving,

- the ability of text analysis and

- the knowledge of the target legal system and the source legal system (Šarčević, 1997: 13-14).

In defining the competences of the translator in the field, the approach based on principles of hermeneutics must be mentioned as well. The hermeneutical translation model was developed by German linguist and translator Radegundis Stolze, who highlighted the importance of the knowledge of legal hermeneutics in legal translation. Her model is founded on the dynamic interconnectedness of all sub-competences. Ac- 


\section{Ljubica Kordić}

cording to Stolze, translation competence encompasses the following key competences necessary for translation of texts from one legal system into another:

- psychological sub-competence, including the ability to analyse and interpret texts;

- thematic sub-competence refers to knowledge of the differences between legal systems and cultures, and the respective legal concepts and terms in two systems;

- textual sub-competence: the ability to interpret and analyse a legal text;

- linguistic sub-competence: knowledge of the source and target languages (Stolze, 2011).

\section{Problems and challenges in teaching legal translation}

\section{Education Programme for Lawyer-Linguists at the Faculty of Law, University of Osijek}

As a response to new job opportunities for Croatian lawyers on the EU market foreign language teachers of the Faculty of Law in Zagreb and the Faculty of Law in Osijek have launched their Lifelong Learning Programmes for Lawyer Linguists. The Programme in Zagreb started in the academic year 2011/12 within the Centre for Language and Law and in Osijek in winter semester 2012/13 within the Lifelong Learning Programmes of the Osijek University.

In 2011, the European Personnel Selection Office (EPSO) of the European Commission announced new job opportunities on the European labour market for Croatian lawyers. According to the data of December 2012, the European Union needed translators, interpreters, lawyer linguists, administrators, heads of departments and other officials in the field of Communication, Legal Affairs and Programme Management in the EU Commission, the Court of Justice of the EU and other institutions. Requirements for the potential employees were graduation from Croatian Law School and thorough knowledge of at least two languages, including English and French or German.

A Lifelong Learning Programme for Lawyer Linguists in Osijek was organized on similar principles as the Programme of the Zagreb Faculty of Law. It was a challenging job, because we wanted to organize a set of courses to respond to new requirements and developments in social and economic life of Croatia after becoming a full member of the EU. However, the new education programme had 
to respond accordingly to the needs of our students and at the same time to be in conformity with specific circumstances in terms of our teaching staff, their specific FL competences, and their individual research background. Taking all these requirements and difficulties into account, the Lifelong Learning Programme for LawyerLinguists was developed within the Strategy of the University of Osijek for the period of time 2011-2020. The Strategy promoted short lifelong learning programmes "...as informal ways of education which should equip citizens with additional competences and skills required by the labour market" (2011: 54).

The Lifelong Learning Programme for Lawyer-Linguists in Osijek was officially accredited by the Senate of the Osijek University and was launched in 2012. Altogether 22 ECTS credits were allocated to the Programme, which encompasses seven courses with altogether 160 teaching hours. The candidates are graduate lawyers with good skills of English and German. The Programme lasts for three months (one semester), and after passing all the exams the candidates are awarded certificates accredited by the University Senate and signed by the Dean of the Faculty. Initially, in the first and the second year of the Programme delivery, the intention was to meet the demands of the EU institutions for skilled legal translators (lawyer-linguists).

Due to the changed demands on the labour market, the motives of our candidates have changed. Therefore, in the academic year 2014/2015, the target group comprised graduate lawyers with good FL skills, who are interested in finding jobs in different EU institutions, in international companies which established business in Croatia, at courts as court interpreters, in export-orientated Croatian firms, etc. So one of the challenges the creators and the performers of the Programme are faced with is that it has to be adjusted to changing needs of participants. Although the initial purpose was to equip the students with competences necessary for the job of lawyer-linguist as required by the European Selection Office, because of the changing circumstances on the market they should be prepared for different legal professions requiring legal and linguistic knowledge.

In the following part I shall describe the courses encompassed by the Programme, followed by a detailed description of the course Introduction to the Theory of Legal Translation and Terminology. Special attention will be paid to competences developed within all courses.

The Programme encompasses the following courses:

1) Introduction to the Theory of Legal Translation and Terminology

2) Croatian Language for Lawyer-Linguists 


\section{Ljubica Kordić}

3) Introduction to the EU Law

4) Introduction to French Legal Translation

5) EU Vocabulary and Online Language Tools

6) Exercises in Legal Translation - the English Language

7) Exercises in Legal Translation - the German Language.

All the courses are obligatory. In the courses Exercises in Legal Translation - the English Language and Exercises in Legal Translation - the German Language, participants are divided in two groups, depending on the fact which FL is their first FL, and which the second FL.

Exercises in Translation of Legal Texts in English and in German are focused on the translation process and possible ways of approaching translation. Specifically, the courses Exercises in Translation of Legal Texts in both languages are focused on the analysis and discussion of

- translations the participants have done as their homework between sessions,

- the translation process itself,

- the specific approach to translation of legal texts,

- specific features of the lexis, syntax, frequent grammar structures of the language of law, and

- collocations and phrases typical of the respective legal language.

Within this course, we develop students' ability to analyse and interpret texts, which includes the awareness that the basic unit of translation is not a word, but a piece of information (psychological competence). Another goal is to develop their ability to interpret and analyse a legal text, to recognize its type and to interpret information from the source language into the target language (textual competence). Before translating any of the texts, participants are instructed to pay attention to possible notional differences between legal systems and cultures of the source language and the target language (thematic competence). Although the precondition for participation in the Programme is that students have a thorough knowledge of English and German, their linguistic competence is constantly improved in the sense of legal language and terminology (linguistic competence).

"Introduction to the EU Law" has been incorporated in the Programme in order to meet the needs of those participants who did not have this course as a part of the curriculum in their regular undergraduate study programme of law. The participants who have passed the exam in EU Law in their regular study time are exempted from attending this course. Although this course is not directly connected with foreign languages, we have included it 
in the Programme because of the importance of knowledge of the EU law and its basic terminology in Croatian language before dealing with EU terminology in English, German and French.

Within the course "The Croatian Language for Lawyer-Linguists", participants are trained in good writing skills and proper use of Croatian orthography and punctuation. In this course, linguistic and textual competences are developed in participants' mother tongue, because in the profession of lawyer-linguists Croatian language is in most cases the target language.

"Introduction to French Legal Translation" is a course focused on teaching general communication in French, including some basic legal terminology. If there are participants who have mastered French at upper levels, they are instructed by an individual approach and get specific translation tasks in the field of law as their homework, which are then discussed and commented by the teacher in the next session. Within this course, similarly to the courses "Exercises in Translation of Legal Texts in English and in German", linguistic, textual, psychological and thematic competences are developed.

The course "EU Vocabulary and Online Language Tools" has been introduced as a response to recent developments in translation methodology. Within this course, students are instructed in using online translation tools: online dictionaries and database, especially EuroTerm, Eurlex, as well as the Croatian EU-terminology database offered on the webpage of the Croatian Institute for Language and Linguistics (Hrvatski institut za jezik i jezikoslovlje) under the acronym STRUNA (strukovno nazivlje terminology in languages for specific purposes). So apart from the aforementioned translation competences, a pragmatic competence is developed within this course.

\section{Teaching legal translation within the course Introduction to the Theory of Legal Translation and Terminology}

The purpose of this course is to pass the basic theoretical knowledge on legal translation to the target group of learners, to equip them with basic communication competences needed in legal translation and to make them aware of all specific sub-competences within the translational competence in the field of law. Being graduate lawyers, they are usually equipped with little or no theoretical linguistic knowledge, which requires a specific approach by the foreign language teacher and thus represents another teaching challenge. 
The syllabus of the course was designed based on

1) Written sources on legal translation: New Approach to Legal Translation by Susan Šarčević (1997), Entwicklungslinien der Translationswissenschaft: Von den Asymmetrien der Sprachen zu den Asymmetrien der Macht by Erich Prunc (2012), and articles by Peter Sandrini and Radegundis Stolze chosen from Übersetzen von Rechtstexten (ed. Peter Sandrini, 1999) and Legal Language in Action (ed. Susan Šarčević, 2009).

2) The results of the research that the teacher teaching this course has conducted in the fields of German, English and Croatian Legal Languages and his/her own experience in translating legal 9texts. Apart from that, as additional reading, every student (candidate) is asked to choose one chapter from the book Comparative Legal Linguistics by Heikki Mattila (2006) and to report on it in his/her exam.

The course design is founded on the comparative content-and-languageintegrated-learning approach (CLIL), that is to say that the course content is given in the English language, but all the examples illustrating the features and facts concerning the translation issue in the field of law are offered in three languages: English, German and Croatian. The course comprises eight basic topics delivered two hours per week during 8 weeks (the duration of the entire Programme is 10 weeks):

1) General features of the language of law

2) Linguistic features of the German, English and the Croatian languages of law (lexis and semantics, morphology, syntax)

3) Translation from the point of view of communication theory

4) Specific features of legal translation - a comparative approach

5) Basics of EU terminology and phraseology - a comparative approach

6) Poetic elements in legal language - a comparative approach

7) Reference to the knowledge and skills developed within the courses Exercises in Legal Translation - German/English

8) Employment procedure in the EU institutions - a report based on own experience (visiting lecturer).

In the first session, general features typical of the language of law are presented and illustrated by using corresponding examples in the three languages. Special attention is paid to:

- polysemy and semantic complexity of legal terms,

- difficulties in understanding (obscurity) of legal texts due to Latin loanwords and abstract terms, nominal style and the frequency of complex sentences,

- numerous types of legal texts with their specific (rigid) structures,

- imprecision and impersonal character of normative texts, and, finally, 
- style of the legislative texts, which is usually defined as clear, precise, exact, objective.

By illustrating these features by specific examples in the three languages, the fact is highlighted that the style of normative texts is also allinclusive and ambiguous at the same time, and thus represents a type of contradiction per se (Bhatia, 2004). Interestingly, the representative of the German school of legal linguistics Dietrich Busse came to the similar conclusion, expressing it in another way and claiming that conflict is at the core of legal language as it is at the core of law (Busse, 2002).

In the second set of lectures the linguistic features of German, English and Croatian legal languages are discussed on the level of lexicology (semantics), morphology and syntax. Special attention is paid to conceptual differences between legal systems and cultures as reflected to asymmetry in legal terms between languages used in those cultures. Every linguistic feature is illustrated by examples in the three languages. The session is concluded by asking students to solve tasks concerning specific features. For example, they should determine the meaning of the word challenge in everyday speech and in the legal language. The term Conflict of Laws should be analysed with reference to the term Private International Law in the Civil Law System. They should translate the word administration/administracija from Croatian into English and German in five different meanings or determine tenses used most frequently in German, English and Croatian normative texts (the passive voice, the active voice, the normative usage of the auxiliary verb shall).

The next session makes students familiar with the translation from the point of view of communication theory. The terms like communication code, communication channel, noise in the communication channel, the sender and the recipient in the translation as communication process are discussed. Special attention is focused on the main factors of the translation process as seen by Prunch: habitus, capital, and field and their specific meanings. Specifically, the fact is highlighted that from the point of view of communication theory, the basic unit of translation process is not a word or sentence, but a piece of information.

The forth session is focused on specific features of legal translation. An overview of different approaches to legal translation is made. Special emphasis is on the principle defined as "Enttrohnung des Ausgangstextes - dethronement of the source language". The principle is illustrated with specific examples of literal, word-by-word translation from one legal system to another, to prove that legal translation is not only a linguistic transfer, but also a transcultural transfer. Recent developments of the modern 


\section{Ljubica Kordić}

translation theory are an important part of this session, with an emphasis on the functionalist approach and the Skopos-theory as defined by Reiss and Vermeer (1984). In this context, the purpose of translation, the target language and the final user of translation as main factors of the translation process are discussed, with specific reference to legal translation. In the final part of the session, specific features of legal translation are highlighted which should be kept in mind, especially conceptual and cultural differences between legal systems and the differences at the linguistic level between English, German, and Croatian legal languages. In this context, Prunc (2012) and Sandrini (2009) and their theoretical approaches to legal translation are mentioned: the former concerning his theory of asymmetry of legal terms in different legal systems and cultures, and the latter with reference to his theory of relative equivalence of legal terms (2009: 154f).

In the fifth session "Basics of EU terminology", students are informed about the standardization of the EU terminology and the importance of consistency in using standardized EU terms in translation concerning EU legal issues, e.g. the Committee of Regions, not: the Regional Committee:

Identical concepts shall be expressed in the same term, as far as possible without departing from their meaning in ordinary, legal or technical language (Joint Practical Guide, EC, 2013)

The list of the most common EU terms in EU legislation and EU institutions in English and German are offered, and students are asked to determine the corresponding Croatian terms. Additionally, new EU terms used in different meaning from that in English dictionaries are discussed as a specific feature of the EU legal vocabulary, like actor, agenda, cabinet, undertaking, etc.

Within the lecture on poetic features of legal language, this phenomenon is observed from a historic perspective. As a motivating introduction to the session, it is pointed out that Jakob Grimm's paper "On the Poetry of the Legal Language" was published in 1816. Examples of metaphor, alliteration, and personification used in legal texts in English, German and Croatian are offered, like, for example, legal remedy/Rechtsmittel/pravni lijek. Alliterations and tautologies in the form of doublets (and triplets) are presented in German and English - students are asked to give the corresponding Croatian expressions:

Zur Last legen/zur Last liegen

Leib und Leben

Notwehr und Notstand null and void

law and order

breaking and entering 
Verbrechen und Vergehen

recht und rechtsmäbig

Handlung oder Unterlassung

Leben und Tod peace and order

last will and testament

act or omission

life and death

As mentioned in the beginning, the final lecture is held by an experienced translator in the EU Commission (a visiting lecturer), who reports on personal experience regarding the employment procedure within the European Personnel Selection Office and the competences required from the candidates for jobs like lawyer-linguists, translators, administrators in translation teams, etc.

In the seventh session, which is planned as summing up of the course, the knowledge acquired on the theory of translation is connected to the knowledge and skills developed within the courses Exercises in Legal Translation - German and Exercises in Legal Translation - English. In this way, the summary of the most important theoretical issues concerning legal translation is made and theoretical knowledge is connected with practical skills. In other words, in this last session on legal translation theory, participants should connect the theoretical knowledge acquired within the course with practical experience from their exercises in translating legal texts from their first foreign language and the second foreign language into Croatian. They are expected to draw conclusions on

- the main factors and principles of legal translation;

- the functionalist approach (skopos-theory);

- the specific features of legal translation that translators should be aware of,

and especially,

- on the key competences of a translator in the field of law.

\section{Competences of legal translators developed within the Programme}

As stated in the previous passage, in the final session the participants of the Lifelong Learning Programme for LawyerLinguists are expected to draw conclusions on the specific competences of a legal translator. The main task of that session is to make the participants aware of those competences and of the necessity that translators should constantly work on developing and internalizing those competences. Assisted by the teacher's medi- 
ation, students are asked to think of the competences that they were trained in within the Programme and to define them. Students are monitored in drawing conclusions about the importance of the following competences in the process of legal translation:

1. Psychological competence: the ability to analyse and interpret texts, which includes the awareness that the basic unit of translation is not a word, but a piece of information;

2. Thematic competence: the knowledge of the differences between legal systems and cultures (Here they should remember Prunc's idea on the importance of the embeddedness of the text in legal and cultural contexts of the source language and the target language (Einbettung des Textes),

3. Textual competence: the ability to interpret and analyse a legal text, to recognize its type and to interpret information from the source language into the target language;

4. Linguistic competence: knowledge of the source language and the target languages, which includes:

- Awareness of differences in legal concepts and terms between two legal systems (asymmetry of legal terms; relative equivalence of legal terms);

- Knowledge of linguistic features of the source language and the target language on the level of lexicology, morphology, syntax, and style, especially with reference to: external and internal polysemy, synonymy, redundancy, nominal style, elliptical expressions, frequent grammar structures etc.;

- Knowledge about metaphors, alliterations, personifications, phrases, doublets, collocations and other stylistic devices of legal style within a specific language.

5. Pragmatic competence: the application of the functionalist approach, which points out the purpose of translation, the target language and the final user of translation as the main factors of the translation process. In this context, students are warned to pay special attention to every piece of information in the source language if the texts to be translated are of the documentary type, and the fact that every piece of information should be transferred into the context of the other legal system and other culture. Within their pragmatic competence, translators should know how to reach reliable sources of information in both languages in order to understand the meaning of the legal term in the source language, and to find the most appropriate term in the target language. In this context, using of translation tools accessible online is pointed out, 
which the participants were trained in within the course EU Vocabulary and Online Translation Tools.

\section{Concluding remarks}

The Education Programme of Lawyer-Linguists was designed according to the real life needs of the target group of learners, so we can say that it is learner-centred. Its purpose is to provide graduate lawyers with additional linguistic knowledge and to develop their translation competences and skills necessary to improve their employment chances. The programme is based on the CLIL-approach and adjusted to specific circumstances of the Osijek Faculty of Law. This specially refers to our teaching staff, its knowledge, competences and research areas - so the translation skills and competences could be developed only in English, German and French language. These languages are traditionally instructed in the region of Slavonia, where the town of Osijek is situated, while French is only learned individually (and rarely), in private schools of foreign languages. Therefore, instructions in French can be offered only on A1 or A2 level, including basics of the EU terminology, although, according to the purpose of the Programme, participants should be instructed in legal French. This represents a restricting factor and another difficulty, along with the limited time planned for the Programme, so only a part of the necessary knowledge and skills can be offered. Nevertheless, our teaching approach of connecting theoretical knowledge with practical translation exercises results in developing the basic competences of a legal translator, and the course on the theory of legal translation makes the future lawyer-linguists or legal translators aware of all the necessary competences, which represents a valuable outcome of the Programme and confirms its pragmatic value.

The theoretical part of this paper, dealing with the translation theories and the competences of translators working in the field of law, has indicated how complex these competences are. The legal translators are faced with demanding tasks, especially with regard to translation of legal texts from one legal system and culture to a conceptually and culturally different legal system. The complexity of translation competences developed within the teaching programme which has been described in this paper, can well illustrate all the difficulties, challenges and limitations that teachers teaching legal translation within informal (lifelong) education programmes at the tertiary education level are confronted with. 
Baker, M. \& Saldanha, G. (Eds.), (2009). Routledge Encyclopedia of Translation Studies. Abingdon: Routledge.

Bhatia, V. K. (2004). Worlds of Written Discourse: A Genre-Based View, London: Continuum.

Busse, D. (2002). Der Stellenwert der Sprachtheorie in der juristischen Methodenlehre. http://www.mauthner-gesellschaft.de/mauthner/tex/buss1ahtml

Kelly, D. (2005). A Handbook for Translator Trainers. Manchester: St Jerome.

Kordić, L. (2010). Elementi neformalnosti i poetičnosti u jeziku prava. In Zbornik radova HDPL: Prostor $i$ vrijeme u jeziku: Jezik u prostoru i vremenu, 175185. [Informal and Poetic Elements in the Language of Law. Proceedings of the CAAL Conference Language in Space and Time, 175-185]. ZagrebOsijek: HDPL and Filozofski fakultet Sveučilišta J.J. Strossmayera.

Mattila, H. (2006). Comparative Legal Linguistics. Ashgate Publishing.

Nord, C. (1997). Translating as a Purposeful Activity. Functionalist Approaches Explained. Manchester: St Jerome.

Prunc, E. (2012). Entwicklungslinien der Translationswissenschaft: Von den Asymmetrien der Sprachen zu den Asymmetrien der Macht. Frank \& Timme.

Reiss, K. Vermeer, H. (1984). Grundlegung einer allgemeinen Translationstheorie. Tübingen: Niemeyer.

Sandrini, Peter (1999) (Ed): Übersetzen von Rechtstexten - Fachkommunikation im Spannungsfeld zwischen Rechtsordnung und Sprache. Tübingen: Gunter Narr Verlag.

Sandrini, P. (2009). Der transkulturelle Vergleich von Rechtsbegriffen. In Šarčević, Susan (Ed.): Legal Language in Action: Translation, Terminology, Drafting and Procedural Issues, 151-167. Zagreb: Globus.

Stolze, R. (2011). The Translator's Approach - Introduction to Translational Hermeneutics: Theory and Examples from Practice. Berlin: Frank \& Timme.

Šarčević, S. (1997). New Approach to Legal Translation. The Hague-LondonBoston: Kluwer Law International.

Šarčević, S. (Ed) (2009). Legal Language in Action. Zagreb: Globus.

Joint Practical Guide. European Commission (2013). http://eur-lex.europa.eu/ content/pdf/techleg/joint-practical-guide-2013-en.pdf

Strategy of the Josip Juraj Strossmayer University of Osijek 2011-2020 (2011). Osijek: J. J. Strossmayer University of Osijek. 